\title{
The Intergenerational Transmission of Education: Evidence from Taiwanese Adoptions
}

\author{
Meng-Wen Tsou \\ Graduate Institute of Industrial Economics, National Central University, Taiwan \\ Jin-Tan Liu \\ Department of Economics, National Taiwan University and NBER \\ James K. Hammitt \\ Harvard University (Center for Risk Analysis) and \\ Toulouse School of Economics (LERNA-INRA)
}

Corresponding author:

James K. Hammitt

Toulouse School of Economics (LERNA-INRA

21 allée de Brienne

310000 Toulouse

France

Tel: +33 5611286 22, Fax: +1 6174320190

Email: jkh@harvard.edu

Acknowledgement:

JKH acknowledges financial support from INRA and the European Research Council under the European Community's Seventh Framework Programme (FP7/2007-2013) Grant Agreement no. 230589 . 


\begin{abstract}
This paper examines the causal effect of parental schooling on children's schooling using a large sample of adoptees from Taiwan. Using birth-parents' education to help control for selective placement of children with adoptive parents, we find that adoptees raised with more highly educated parents have higher educational attainment, measured by years of schooling and probability of university graduation. We also find evidence that adoptive father's schooling is more important for sons' and adoptive mother's schooling is more important for daughters' educational attainment. These results support the notion that family environment (nurture) is important in determining children's educational outcomes, independent of genetic endowment.
\end{abstract}

Keywords: intergenerational transmission, education, schooling, adoption

JEL Classification: I21, J62 


\section{Introduction}

The positive association between parental and child schooling has been well documented in the intergenerational-mobility literature. Only recently, however, have studies emerged identifying the causal effect of parental background on children's outcomes. Distinguishing between selection and causation is important for designing education policies. If parental schooling provides a better family environment for children, increasing schooling of one generation will reduce past inequalities in education. Alternatively, if children's ability is primarily inherited, improvement in home environment may have limited effect and inequalities in schooling may persist across generations.

Researchers have employed three strategies to identify a causal effect of parental education on children's education: studying adopted children or identical twins and using instrumental variables (Holmlund, Lindahl and Plug, 2011). The adoption strategy relies on the absence of genetic transmission between adoptive parents and adopted children. If adopted children are randomly assigned to adoptive families, then any relationship between adoptees' and their adopted parents' outcomes is driven by family environment but not genetics. The twins approach exploits the idea that effects of unobserved parental endowments can be differenced out between twin children. The instrumental variable approach takes advantage of education reforms where changes in compulsory schooling laws are used to instrument for parental education. Studies differ in context, data, and identifying strategies and the resulting evidence is quite mixed.

This study employs the adoption approach. Sacerdote (2002) uses a small sample of Korean adoptees in the U.S. to find that adoptees raised in higher socioeconomic-status families have significantly higher probabilities of college attendance and that adoptive mother's schooling has a positive and significant effect on children's schooling. In contrast, Plug and Vijverberg (2003), 
using data from the Wisconsin Longitudinal Survey, suggest that genetics (measured as parental IQ) is the primary factor in explaining schooling differences among children. Plug (2004) employs the same data to compare the intergenerational transmission of education between own-birth and adopted children. Controlling for assortative mating, he finds that the paternal schooling effect for adoptees remains positive and significant but the maternal schooling effect is insignificant. Björklund et al. (2006) were the first to use information on adoptees' biological parents to control for selective placement. They use a sample of Swedish adoptees to conclude that both nature and nurture contribute to intergenerational transmission of education. They find the effects from biological and adoptive fathers are comparable but the effects from biological mothers exceed those from adoptive mothers. Utilizing samples of Swedish-born and foreign-born adoptees, Holmlund et al. (2011) find similar but smaller effects of maternal schooling and paternal schooling on children.

This paper contributes to the existing literature by using a unique Taiwanese dataset with information on adopted children's biological and adoptive parents to estimate intergenerational transmission of educational attainment. To our knowledge, this is the first study to provide direct evidence for a recent cohort in Asia. Taking birth parents' education into account, we find that adoptive parents' education has a causal effect on children's education. The stronger association of children's education with adoptive than with birth parents' education suggests the parental effect is driven more by nurture than by nature. Our results also show different effects between sons and daughters: the paternal effect is more important for sons and maternal effect is more important for daughters.

\section{Data}

We linked the 2006 Taiwanese household-register data to the national birth certificate record 
data for 1978-1984. The household-register data contain multigenerational information about households, including the relationships between household members and household head, each member's birth place, marital status, educational attainment, and whether he/she is adopted. Comprehensive details on gender, birth weight, and birth order are provided by the birth certificate files, together with the parents' ages and years of education at the time of the birth. We used the unique personal identifier to merge the household-register data with birth certificate files and restrict our sample to the cohort aged 22-28 years in 2006.

The main advantages of this dataset are twofold: (1) it is a comprehensive national dataset providing a large sample with high-quality data; (2) it contains information on both adoptive and biological parents of adoptees, which enables us to control for effects of selective placement. A limitation is that age at adoption is unavailable. Since evidence shows that a vast majority of Taiwanese adoptions took place within a year of the child's birth, we implicitly assume that adoption took place near birth.

Given that the key identifying assumption is that adoptees are assigned randomly to adoptive families, we exclude stepparent adoptions and adopted children whose siblings in the household have a common grandfather or grandmother. After excluding observations with missing values on parental characteristics, we retain 4,557 adopted children and 1,437,453 own-birth children for analysis.

Two striking features of adoptions in Taiwan are that most adoptees are female (about two-thirds of our sample) and are of higher birth parity (mean =4.1 vs. 2.0). Adoptive parents average 3-6 years older at child's birth than own-birth children's parents, as most Taiwanese parents adopt only after failing to bear their own children. On average, adopted children have 0.5 years less schooling and 10 percentage points smaller frequency of university education than own-birth children. Own-birth children's fathers have 2.5 more years of schooling than adopted 
children's birth fathers and are more frequently university graduates (11 vs. 3 percent).

Compared with adopted children's birth parents, adoptive parents are more educated: average schooling is 1.8 years larger for adoptive fathers and 1.7 years larger for adoptive mothers. Positive correlations of schooling between adoptive and biological fathers/mothers $(0.21 / 0.23)$ suggest non-random sorting of adoptees to adoptive families.

\section{Empirical Results}

Table 1 reports least-squares estimates for years of schooling and marginal-effect estimates for a probit model for the likelihood of university education. The results for own-birth and adoptive children are presented in separate panels. All specifications include controls for child's gender, birth weight, and parents' ages at birth plus birth year and region.

For own-birth children, we first include father's and mother's schooling in separate regressions. We find that children's schooling and university graduation are significantly associated with each parent's schooling. An additional year of father's/mother's education is associated with $0.19 / 0.15$ additional years of child's schooling. A father/mother with university education is associated with a $25 / 22$ percent higher likelihood that their child will graduate university. When we include both parents' schooling simultaneously, the estimated effects are reduced but remain statistically significant, with the father's education (0.12) having a larger effect than the mother's (0.08). Similar results are found for university education. Consistent with expectations, children with birth weight lower than 2,500g or higher birth order have fewer years of schooling and smaller probabilities of university graduation.

For adopted children, we first examine separate transmission effects from biological and adoptive fathers and mothers. The schooling coefficients of both adoptive and biological parents are statistically significant, with the magnitudes of effects for adoptive parents about twice as 
large as those for biological parents. When including all parents' schooling, the coefficients are smaller but remain statistically significant. Consistent with results of Björklund et al. (2006) for Sweden, we find both adoptive and biological parents' schooling matter, which suggests that both nature and nurture are important in determining children's educational attainment.

Compared with their results, we have somewhat larger schooling effects for adoptive parents and smaller effects for biological parents. In separate regressions for sons and daughters (Table 2), we find that the adoptive father's education is more important for sons and the adoptive mother's education is more important for daughters.

Results for university education are similar. The chance that an adopted child is university-educated is positively associated with having university-educated adoptive and biological parents. The estimated effect is larger for adoptive than for biological parents, with the coefficients for biological parents becoming insignificant when controlling for adoptive parents' education.

Data limitations prevent us from making strong inferences. For example, there may be unobserved differences between adoptive and birth parents, between adoptive and own-birth children, or in the interactions between birth and adoptive parents and children. We conduct a series of sensitivity tests for these effects. First, we use a sample of own-birth children raised with adopted siblings to investigate whether adoptive parents are different from other parents. Our results for own-birth children with adopted siblings are similar to those for children without adopted siblings. If parents have a tendency to favor their own offspring over adoptees, then we should expect that adoptees with own-birth siblings do relatively worse in school. However, we do not find treatment differences among adoptees with or without own-birth siblings. Finally, we restrict analysis to a sample of own-birth children whose siblings were adopted out of their families. We find the paternal effect is somewhat larger and the maternal effect somewhat 
smaller than those observed for all own-birth children. Overall, there is little evidence that unobserved differences between adoptive and own-birth families confound our results.

\section{Conclusions}

We use data on adoptees in Taiwan to identify the causal effect of parental schooling on children's schooling. We find that biological and adoptive father's and mother's schooling are positively and significantly associated with the child's schooling. The associations with adoptive parents' education are stronger than those with biological parents' education, especially for university attendance. Moreover, we find evidence that the adoptive father's schooling is more important for sons and adoptive mother's schooling is more important for daughters. Our results suggest that family environment is indeed an important source of intergenerational transmission of education. 


\section{References}

Björklund, A., Lindahl, M., Plug, E., 2006. The origins of intergenerational associations: Lessons from Swedish adoption data. Quarterly Journal of Economics 121, 999-1028.

Holmlund, H., Lindahl, M., Plug, E., 2011. The causal effect of parent's schooling on children's schooling: A comparison of estimation methods. Journal of Economic Literature, forthcoming.

Plug, E., 2004. Estimating the effect of mother's schooling on children's schooling: Using a sample of adoptees. American Economic Review 94, 358-368.

Plug, E., Vijverberg, W., 2003. Schooling, family background, and adoption: Is it nature or is it nurture? Journal of Political Economy 111, 611-641.

Sacerdote, B., 2002. The nature and nurture of economic outcomes. American Economic Review Papers and Proceedings 92, 344-348. 
Table 1. Estimates of Intergenerational Effects of Schooling : Own-birth Children and Adopted Children Years of schooling University education

(1)

(2)

(3)

(4)

Own-birth children

Biological father

0.1855

$(0.0005)^{* * *}$

0.1235

0.2522

$(0.0006)^{* * *}(0.0010)^{* * *}$

0.1968

Biological mother

$0.1512 \quad 0.0830$

$(0.0006)^{* * *}(0.0006)^{* * * *}$

0.2177

$(0.0012)^{* * *}$

0.1258

$(0.0016)^{* * *}$

Adopted children

Biological father

0.0691

$(0.0105)^{* * *}$

Biological mother

Adoptive father

Adoptive mother

0.1185
$(0.0090)^{* * *}$

$\begin{array}{cc}0.0452 & 0.1153 \\ (0.0110)^{* * *} & (0.0437)^{* * *}\end{array}$

$\begin{array}{cc}0.0690 & 0.0397 \\ (0.0110)^{* * *} & (0.0118)^{* * *}\end{array}$

$(0.0106)^{* * *}(0.0218)^{* * *}$

0.0650

(0.0484)

0.1235

(0.0877)

0.2172

$(0.2172)^{\text {**** }}$

$\begin{array}{ccc}0.1213 & 0.0724 & 0.2548 \\ (0.0099)^{* * * *} & (0.0116)^{* * *} & (0.0348)^{* * *}\end{array}$

0.1173 $(0.0469)^{* * * *}$

Notes: Robust standard errors are shown in parentheses. All regressions include controls for child's gender, low birthweight dummy, birth order, birth year, region of birth, and the respective parents' age at birth. $* * *$ represents statistical significance at 1 percent level. 
Table 2. Estimates of Intergenerational Effects of Schooling by Gender: Own-birth Children and Adopted Children

\begin{tabular}{|c|c|c|c|c|c|c|}
\hline \multirow{3}{*}{$\overline{\text { Own-birth children }}$} & \multicolumn{3}{|c|}{ Sons } & \multicolumn{3}{|c|}{ Daughters } \\
\hline & (1) & (2) & (3) & (4) & (5) & (6) \\
\hline & & & & & & \\
\hline Biological father & $\begin{array}{c}0.2115 \\
(0.0007)^{* * *}\end{array}$ & & $\begin{array}{c}0.1427 \\
(0.0009)^{* * * *}\end{array}$ & $\begin{array}{c}0.1530 \\
(0.0007)^{* * *}\end{array}$ & & $\begin{array}{c}0.0994 \\
(0.0009)^{* * *}\end{array}$ \\
\hline Biological mother & & $\begin{array}{c}0.1704 \\
(0.0008)^{* * * *}\end{array}$ & $\begin{array}{c}0.0925 \\
(0.0009)^{* * * *}\end{array}$ & & $\begin{array}{c}0.1277 \\
(0.0008)^{* * *}\end{array}$ & $\begin{array}{c}0.0721 \\
(0.0009)^{* * *}\end{array}$ \\
\hline Observations & & 810305 & & & 627148 & \\
\hline Adopted children & & & & & & \\
\hline Biological father & $\begin{array}{c}0.0410 \\
(0.0184)^{* *}\end{array}$ & & $\begin{array}{c}0.0225 \\
(0.0193)\end{array}$ & $\begin{array}{c}0.0841 \\
(0.0126)^{* * *}\end{array}$ & & $\begin{array}{c}0.0569 \\
(0.0132)^{* * *}\end{array}$ \\
\hline Biological mother- & & $\begin{array}{c}0.0572 \\
(0.0202)^{* * * *}\end{array}$ & $\begin{array}{c}0.0341 \\
(0.0213)\end{array}$ & & $\begin{array}{c}0.0659 \\
(0.0126)^{* * *}\end{array}$ & $\begin{array}{c}0.0429 \\
(0.0138)^{* * *}\end{array}$ \\
\hline Adoptive father & $\begin{array}{c}0.1555 \\
(0.0166)^{* * * *}\end{array}$ & & $\begin{array}{c}0.1234 \\
(0.0193)^{* * *}\end{array}$ & $\begin{array}{c}0.0997 \\
(0.0106)^{* * *}\end{array}$ & & $\begin{array}{c}0.0537 \\
(0.0126)^{* * *}\end{array}$ \\
\hline Adoptive mother & & $\begin{array}{c}0.1245 \\
(0.0181)^{* * * *}\end{array}$ & $\begin{array}{c}0.0554 \\
(0.0204)^{* * * *}\end{array}$ & & $\begin{array}{c}0.0973 \\
(0.0140)^{* * *}\end{array}$ & $\begin{array}{c}0.0826 \\
(0.0140)^{* * *}\end{array}$ \\
\hline Observations & & 1577 & & & 2980 & \\
\hline
\end{tabular}

Notes: Robust standard errors are shown in parentheses. All regressions include controls for child's gender, low birthweight dummy, birth order, birth year, region of birth, and the respective parents' age at birth. *** and ** represent statistical significance at 1 and 5 percent level respectively. 